\title{
Correlations between related-purine derivatives and renal disorders in patients with psoriasis vulgaris
}

\author{
ILINCA NICOLAE $^{1 *}$, MIRCEA TAMPA $^{1,2^{*}}$, CORINA DANIELA ENE $^{3 *}$, \\ CRISTINA IULIA MITRAN ${ }^{1,4^{*}}$, MADALINA IRINA MITRAN ${ }^{1,4^{*}}$, MARIA ISABELA SARBU $^{2 *}$, \\ CLARA MATEI $^{2 *}$, COSMIN ENE $^{5^{*}}$ and SIMONA ROXANA GEORGESCU ${ }^{1,2 *}$ \\ ${ }^{1}$ Department of Dermatology, 'Victor Babes' Clinical Hospital for Infectious Diseases, 030303 Bucharest; \\ ${ }^{2}$ Department of Dermatology, 'Carol Davila' University of Medicine and Pharmacy, 020021 Bucharest; \\ ${ }^{3}$ Department of Nephrology, 'Carol Davila' Nephrology Hospital, 010731 Bucharest; Departments of \\ ${ }^{4}$ Microbiology and ${ }^{5}$ Urology, 'Carol Davila' University of Medicine and Pharmacy, 020021 Bucharest, Romania
}

Received August 03, 2018; Accepted September 05, 2018

DOI: $10.3892 /$ etm.2018.7053

\begin{abstract}
Recent data suggest that severe psoriasis is an independent risk factor for chronic renal disease. In the present study, we investigated the role of related-purine derivatives as predictors of renal dysfunctions in patients with psoriasis. A prospective study was conducted on a group of 45 patients with psoriasis vulgaris and 45 control cases, monitored over a 5-year period. Alterations of renal function, albumin/creatinine ratio (ACR, $\mathrm{mg} / \mathrm{g}$ ) and UA/creatinine ratio (UACR, $\mathrm{mg} / \mathrm{mg}$ ) were determined in spontaneous urine samples. The status of related-purine derivatives was evaluated by quantification of uric acid (UA, mg/dl), adenosine deaminase (ADA, UI/mg protein), xanthine oxidase (XO, $\mathrm{UI} / \mathrm{mg}$ protein) and 8-hydroxy-deoxy-guanosine levels (8-OHdG, $\mathrm{ng} / \mathrm{ml})$ in serum samples. Compared to the controls, in patients with psoriasis there was an increase in related-purine derivatives levels, which was demonstrated by the elevated serum levels of UA $(5.1 \pm 0.4$ vs. $5.4 \pm 1.0$, $\mathrm{P}=0.066)$, ADA $(0.14 \pm 0.08$ vs. $0.29 \pm 0.12, \mathrm{P}=0.052), \mathrm{XO}$ $(0.22 \pm 0.11$ vs. $0.42 \pm 0.21, \mathrm{P}=0.011)$ and $8-\mathrm{OHdG}(3.1 \pm 0.05$ vs. $8.3 \pm 4.7, \mathrm{P}=0.002$ ). The serum levels of related-purine derivatives were associated with the severity of psoriasis. In addition, there was a link between the serum levels of related-purine derivatives and markers of renal impairment. There were positive correlations between $8-\mathrm{OHdG}$ and ACR $(\mathrm{r}=0.452, \mathrm{P}=0.028)$ and between ADA, XO, UA, 8-OHdG and UACR $(r=0.297$ and $\mathrm{P}=0.032, \mathrm{r}=0.301$ and $\mathrm{P}=0.002, \mathrm{r}=0.431$
\end{abstract}

Correspondence to: Dr Mircea Tampa, Department of Dermatology, 'Victor Babes' Clinical Hospital for Infectious Diseases, 281 Mihai Bravu, 030303 Bucharest, Romania

E-mail: tampa_mircea@yahoo.com

*Contributed equally

Key words: psoriasis, purine derivatives, uric acid, kidney disease, serological markers and $\mathrm{P}=0.027, \mathrm{r}=0.508$ and $\mathrm{P}=0.002$ ) and negative correlations between UA, 8-OHdG and the estimated glomerular filtration rate $(\mathrm{r}=-0.301$ and $\mathrm{P}=0.036, \mathrm{r}=-0.384$ and $\mathrm{P}=0.002)$. Thus, severe psoriasis is a risk factor for the development of renal disease.

\section{Introduction}

Psoriasis is a chronic immunologically mediated dermatosis, affecting 2-3\% of the general population (1-3). Multiple mechanisms are involved in its pathogenesis, such as the hyper-reactivity of T-lymphocytes and dendritic cells, excessive inflammatory cytokine synthesis, accelerated epidermal turnover, epidermal hyperproliferation, reduced keratinocyte differentiation, overexpression of angiogenesis and oxidative stress (4-14). The extent of skin involvement is variable, ranging from several psoriatic plaques to generalized forms. The disease evolves with periods of exacerbation and remission $(15,16)$.

It seems that severe psoriasis is an independent risk factor for chronic renal disease $(17,18)$. The mechanisms that mediate kidney failure in patients with psoriasis are controversial. In a retrospective study, it was estimated that patients with psoriasis develop chronic renal disease at a higher percentage compared to controls (5 vs. 2\%). Moreover, the risk of kidney disease was higher in the young patients (18). The treatment should be adapted to meet the individual needs of the patients with psoriasis. Non-pharmacological interventions (diet, cessation of smoking and alcohol intake, weight loss, physical exercise) may improve the response to therapy. Potentially nephrotoxic drugs should be used with caution and renal function should be periodically monitored in patients with psoriasis in order to minimize the risk of adverse renal events $(13,15,19,20)$.

In medical literature, there are few studies on the relationship between uremic toxins and the decline of renal function in patients with psoriasis vulgaris. Recent data suggest the role of several serum and urinary markers in the early detection and monitoring of renal disease. The urinary levels of creatinine, albumin, uric acid (UA) and the estimated glomerular 
filtration rate (eGFR) can be evaluated, as well as cystatin $\mathrm{C}$, neutrophil gelatinase-associated lipocalin, kidney injury molecule 1, cytokines and chemokines (21). The progressive increase in the level of uremic toxins exerts a negative impact on kidney function (22-25).

Purine derivatives pertain to the class of low molecular weight uremic toxins, which frequently accumulate in the body. Low molecular weight uremic toxins are water-soluble compounds with a molecular weight below $0.5 \mathrm{kDa}$, and consequently are easily removed by dialysis, and do not exert harmful effects on the body $(26,27)$. The most important uremic toxins classified as purine derivatives are: Products resulted from the degradation of purines (adenosine, inosine, xanthine, guanosine, hypoxanthine, guanine, UA), products of guanosine triphosphate catabolism (neopteri n) and oxidative DNA base damage product (8-hydroxy-deoxy-guanosine) (28-30). The metabolic pathways of purine catabolism imply several phases (31).

The first step involves the transformation of purine mononucleotides (AMP-adenosine monophosphate, IMPinosine monophosphate, XMP-xanthine monophosphate and GMP-guanine monophosphate) into purine nucleosides (adenosine, inosine, xanthosine and guanosine), a reaction catalyzed by 5-nucleotidase (E.C.3.1.3.5). Subsequently, conversion of purine nucleosides occurs which frees purine bases (adenine, hypoxanthine, xanthine and guanine), a reaction catalyzed by purine nucleoside phosphorylase (E.C.2.2.2.1). The next step involves the conversion of adenine to hypoxanthine (a reaction catalyzed by adenine deaminase - E.C.3.5.4.4) and then to xanthine (a reaction catalyzed by xanthine oxidase - E.C.1.17.3.2). Guanine is converted to xanthine by guanine deaminase. The final product of purine metabolism is UA, obtained through the enzymatic oxidation of xanthine (a reaction catalyzed by xanthine oxidase) (Fig. 1).

In psoriasis patients, the severity of the skin disease, assessed by the Psoriasis Area Severity Index (PASI), has been analyzed in relation to the prevalence of renal dysfunctions $(3,16,18,32,33)$, purine catabolism (4) and the oxidative stress level $(5,6,34)$. Alteration of purine degradation may be associated with the extension of psoriasis lesions, stimulation of epidermal proliferation and increased DNA peroxidation (6,35-38).

These reactions produce a wide range of reactive oxidants: hydrogen peroxide $\left(\mathrm{H}_{2} \mathrm{O}_{2}\right)$, superoxide anion $\left(\mathrm{O}_{2}{ }^{\circ-}\right)$, hydroxyl radical $\left(\mathrm{OH}^{\circ}\right)$, nitric oxide $\left(\mathrm{NO}^{\circ}\right)$, peroxynitrite $\left(\mathrm{ONOO}^{-}\right)$, and carbonate radical $\left(\mathrm{CO}^{\circ}\right)$. Reactive oxygen species and reactive nitrogen species, formed under the action of xanthine oxidase, act on proteins, lipids and nucleic acids, causing damage and cell toxicity (39-42). 8-Hydroxy-deoxyguanosine, a representative metabolite for purine derivatives toxins (43), is a useful indicator for early diagnosis and management of patients with psoriasis (6).

Based on these considerations, we aim to establish characteristic patterns of related-purine derivatives that could represent specific serological markers for the identification of those patients with psoriasis vulgaris at a higher risk of developing renal dysfunctions. In this context, the serum profile of related-purine derivatives was analyzed in psoriasis patients in correlation with the severity of the skin disease and markers of renal impairment. The biomarkers carried out in this study, grouped under the name of relatedpurine derivatives, include UA (the final product of purine catabolism), adenosine deaminase (ADA, an enzyme which converts irreversibly adenosine and deoxyadenosine to inosine and deoxy-inosine), xanthine oxidase ( $\mathrm{XO}$, which catalyzes the oxidation of hypoxanthine to xanthine as well as the oxidation of xanthine to UA) and 8-hydroxy-deoxy-guanosine (8-OHdG, a biomarker of oxidative DNA damage). Renal function was assessed through the serum creatinine level, urinary determinations of eGFR ( $\mathrm{ml} / \mathrm{min} / 1.73 \mathrm{mp})$, albumin/creatinine ratio $(\mathrm{ACR}, \mathrm{mg} / \mathrm{g}$ ) and $\mathrm{UA}$-creatinine ratio (UACR, $\mathrm{mg} / \mathrm{mg}$ ).

\section{Materials and methods}

Study participants. All the study participants provided consent to the use of their biological samples in research studies. The Ethics Committee of 'Victor Babes' Clinical Hospital for Infectious Diseases (Bucharest, Romania) approved the study protocol.

A prospective study was conducted on 45 patients with psoriasis vulgaris and 45 control cases, monitored over a 5-year period. Inclusion criteria for the study were: Adults, normolipidemic, normoponderal, with a balanced diet. Exclusion criteria for the study were: Cardiovascular disease, metabolic syndrome, diabetes, anemia, urinary tract infections, nephrolithiasis, leukemia, Lesch-Nyhan syndrome, Wilson's disease, viral hepatitis, sickle-cell disease, chronic kidney disease, xanthinuria, lead toxicity, treatment with nephrotoxic drugs, folic acid deficiency, pregnant women and breastfeeding women.

The severity of psoriasis was assessed using the PASI score, which assesses the severity of three clinical signs (erythema, thickness, scaling) on a scale from 0 to 4 and the percentage of the skin area involved. The PASI score interpretation was as follows: $<7$, mild chronic plaque-type psoriasis; 7-12, moderate chronic plaque-type psoriasis; $>12$, severe chronic plaque-type psoriasis (41).

Changes of glomerular permeability were detected by determining eGFR, ACR and UACR. To assess alterations of renal function, ACR and UACR were determined in spontaneous urine samples. The status of related-purine derivatives was evaluated by quantification of the serum levels of UA $(\mathrm{mg} / \mathrm{dl})$, adenosine deaminase (UI/mg protein), XO (UI/mg protein) and 8-OHdG (ng/ml).

Biological samples were a spontaneous urine sample, preferably first morning urine collected in sterile, preservative-free containers. Urine specimens were centrifuged at 3,000 x g for $10 \mathrm{~min}$ at room temperature $20^{\circ} \mathrm{C}$. The supernatant was used for measurement of the biological parameters. Venous blood samples $(7 \mathrm{ml})$ were collected in a vacutainer without an anticoagulant and centrifuged at $6,000 \mathrm{x}$ g for $10 \mathrm{~min}$ at $20^{\circ} \mathrm{C}$. The supernatant was used for biochemical determinations.

Laboratory methods. The determination of creatinine was performed using the colorimetric technique. The method is based on the reaction between creatinine and picric acid in alkaline medium. The absorbance measured at a wavelength of $492 \mathrm{~nm}$ is directly proportional to the amount of creatinine in the sample. 


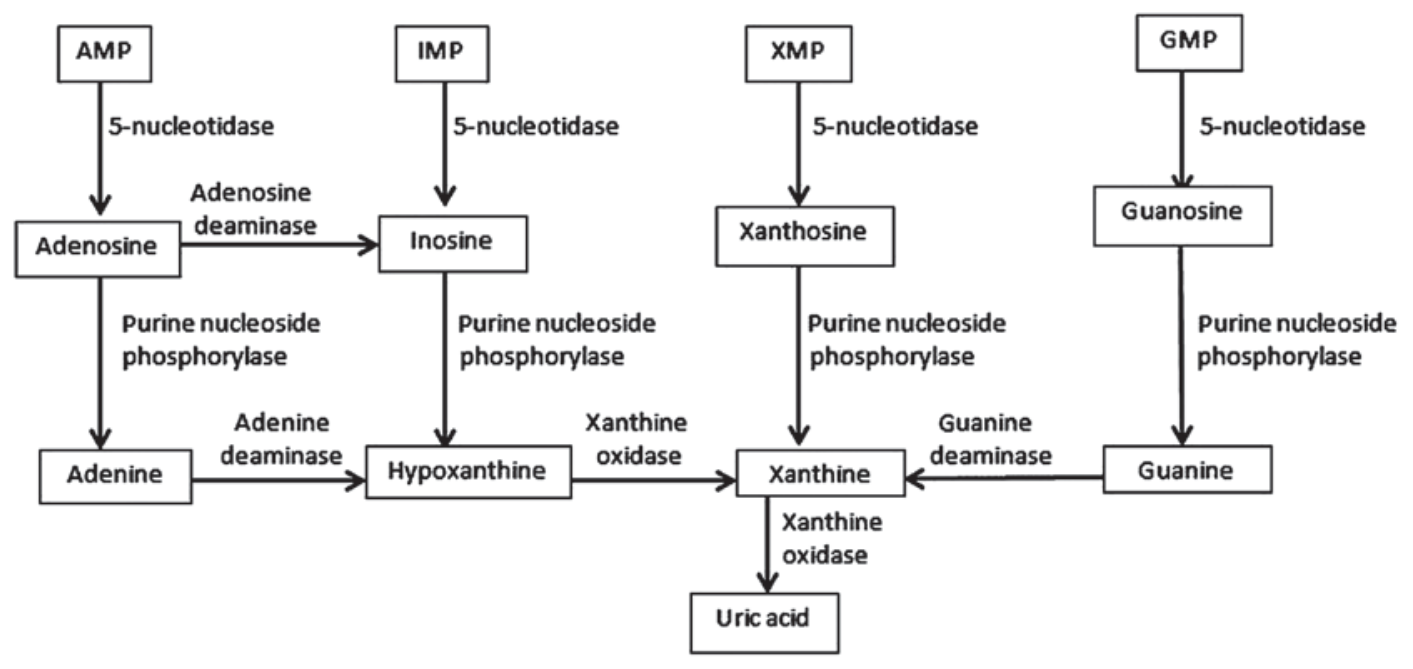

Fig. 1. The metabolic pathways of purine degradation.

The determination of albuminuria was performed via turbidimetric immunoassay using polyclonal antibodies against human albumin. The determination of UA was performed by the colorimetric technique, using the reaction catalyzed by uricase. The concentration of quinonimine resulted from the reaction was determined by measuring the absorbance at a wavelength of $546 \mathrm{~nm}$. The determination of xanthine-oxidase was performed using a spectrophotometer (HumaStar 300; HUMAN Gesellschaft für Biochemica und Diagnostica mbH, Germany, Wiesbaden). Absorbance of the obtained coloured complex was read at a wavelength of $570 \mathrm{~nm}$. The determination of adenosine deaminase was performed via spectrophotometry and the evaluation of the resulting product was measured at a wavelength of $550 \mathrm{~nm}$.

The quantitative determination of hs $8-\mathrm{OHdG}$ (highly sensitive oxidative DNA adduct $8-\mathrm{OHdG}$ ) was produced in serum using an enzyme-linked immunosorbent assay (ELISA). The principle of the method is based on the ability of DNA oxidation products to interact with 3,3,5,5-tetramethylbenzidine. The method uses DNA-specific monoclonal antibodies, which cross-react with the oxidative degradation products of DNA (8-hydroxy-guanine, 8-hydroxyguanosine). The final product of the reaction is colorimetrable via microplate reader (Tecan Austria $\mathrm{GmbH}$, Grodig, Austria) at a wavelength of $450 \mathrm{~nm}$.

Statistical analysis. A comparison of the obtained results between the groups for quantitative variables was performed using the t-test. The correlations between variables were determined by linear regression. The relationship between pairs of two parameters was assessed by Pearson's correlation coefficient (r). We chose a significance level (p) of $0.05(5 \%)$ and a confidence interval of $95 \%$ for hypothesis testing.

\section{Results}

Patient characteristics. We performed a prospective observational study on 45 patients with psoriasis vulgaris (duration of psoriasis $6.4 \pm 3.1$ years, PASI $10.4 \pm 5.3$ ) and 45 healthy volunteers, who met the inclusion criteria (Table I).
Table I. Characteristics of study participants.

\begin{tabular}{lccr}
\hline Items & $\begin{array}{c}\text { Psoriasis } \\
\text { vulgaris }\end{array}$ & Control & P-value \\
\hline Age (years) & $40.3 \pm 11.3$ & $39.4 \pm 8.3$ & 0.763 \\
$\begin{array}{l}\text { Male/female ratio } \\
\text { Smokers/non-smokers }\end{array}$ & $11 / 34$ & $25 / 20$ & 0.923 \\
ratio & $9 / 36$ & 0.755 \\
BMI $\left(\mathrm{kg} / \mathrm{m}^{2}\right)$ & $20.4 \pm 1.3$ & $19.8 \pm 1.1$ & 0.899 \\
$\begin{array}{l}\text { Systolic blood } \\
\text { pressure (mmHg) }\end{array}$ & $117.3 \pm 0.7$ & $115.5 \pm 0.5$ & 0.677 \\
$\begin{array}{l}\text { Diastolic blood } \\
\text { pressure (mmHg) }\end{array}$ & $72.3 \pm 0.2$ & $73.5 \pm 0.4$ & 0.546 \\
\hline
\end{tabular}

BMI, body mass index.

Serum determinations. The serum concentration of UA was $5.4 \pm 1.8 \mathrm{mg} / \mathrm{dl}$ in patients with psoriasis vulgaris and $5.1 \pm 0.4 \mathrm{mg} / \mathrm{d}$ l in the control group, with statistically insignificant variations between the two groups. There was an important difference between the activity of ADA in patients with psoriasis vulgaris and controls $(0.29 \pm 0.12 \mathrm{UI} / \mathrm{mg}$ protein vs. $0.14 \pm 0.08 \mathrm{UI} / \mathrm{mg}$ protein, $\mathrm{P}=0.052)$. The activity of $\mathrm{XO}$ was also significantly increased in psoriasis patients versus controls $(0.42 \pm 0.21 \mathrm{UI} / \mathrm{mg}$ protein vs. $0.22 \pm 0.11 \mathrm{UI} / \mathrm{mg}$ protein, $\mathrm{P}=0.011$ ). The serum level of $8-\mathrm{OHdG}$ in patients with psoriasis vulgaris was significantly higher compared to controls $(8.3 \pm 4.7 \mathrm{ng} / \mathrm{ml}$ vs. $3.1 \pm 0.05 \mathrm{ng} / \mathrm{ml}, \mathrm{P}=0.002)$ (Table II).

Urinary determinations. Since the creatinine excretion is a relatively constant variable, the determination of urinary creatinine may be valuable in estimating the renal function. Therefore, the urinary creatinine concentration can be used as a reference parameter for albuminuria and UA. Statistically significant variations were observed for ACR and UACR between patients with psoriasis vulgaris and controls (Table III). 
Table II. Serum determinations in psoriasis patients and controls.

\begin{tabular}{lccr}
\hline Items & $\begin{array}{c}\text { Psoriasis } \\
\text { vulgaris }\end{array}$ & Control & P-value \\
\hline Glucose (mg/dl) & $88.2 \pm 5.3$ & $81.4 \pm 5.1$ & 0.654 \\
ASAT (U/l) & $18.4 \pm 3.5$ & $21.8 \pm 6.3$ & 0.341 \\
ALAT (U/l) & $16.0 \pm 7.2$ & $17.3 \pm 4.3$ & 0.549 \\
Cholesterol (mg/dl) & $155.3 \pm 11.5$ & $146.3 \pm 12.6$ & 0.388 \\
Tryglicerides (mg/dl) & $82.5 \pm 5.3$ & $76.9 \pm 10.4$ & 0.426 \\
Urea (mg/dl) & $39.3 \pm 4.5$ & $30.4 \pm 5.3$ & 0.088 \\
CRP (mg/dl) & $0.37 \pm 0.24$ & $0.19 \pm 0.19$ & 0.072 \\
Creatinine (mg/dl) & $0.88 \pm 0.12$ & $0.73 \pm 0.07$ & 0.068 \\
UA (mg/dl) & $5.4 \pm 1,8$ & $5.1 \pm 0.4$ & 0.066 \\
ADA (U/mg protein) & $0.29 \pm 0.12$ & $0.14 \pm 0.08$ & 0.052 \\
XO (U/mg protein) & $0.42 \pm 0.21$ & $0.22 \pm 0.11$ & 0.011 \\
8-OHdG (ng/ml) & $8.3 \pm 4.7$ & $3.1 \pm 0.05$ & 0.002 \\
& & & \\
\hline
\end{tabular}

ASAT, aspartate transaminase; ALAT, alanine aminotransferase; U/L, unit level; CRP, $\mathrm{C}$ reactive protein; $\mathrm{UA}$, uric acid; $\mathrm{ADA}$, adenosine deaminase; XO, xanthine oxidase; 8-OHdG, 8-hydroxy-deoxyguanosine.

Correlation of serum levels of related-purine derivatives with the severity of psoriasis. Compared to the controls, UA, ADA, $\mathrm{XO}$ and $8-\mathrm{OHdG}$ levels were significantly higher in patients with psoriasis with PASI $>12(\mathrm{P}<0.05)$ (Table IV).

Positive correlations between ADA, XO, UA and PASI $>12$ $(\mathrm{r}=0.498, \mathrm{P}=0.004 ; \mathrm{r}=0.601, \mathrm{P}<0.001$ and $\mathrm{r}=0.421, \mathrm{P}=0.017)$ were obtained. There was a strong positive correlation between the serum levels of $8-\mathrm{OHdG}$ and PASI $(\mathrm{r}=0.406$, $\mathrm{P}=0.008$ for PASI ranging from 7 to $12, \mathrm{r}=0.782, \mathrm{P}=0.000$ for PASI >12) (Table V).

Correlations between serum related-purine derivatives and markers of renal impairment. Serum markers of relatedpurine derivatives in patients with psoriasis were associated with markers of renal impairment. Positive correlations between $8-\mathrm{OHdG}$ and ACR $(\mathrm{r}=0.452, \mathrm{P}=0.028)$, between ADA, XO, UA, 8-OHdG ( $\mathrm{r}=0.297$ and $\mathrm{P}=0.032 ; \mathrm{r}=0.031$ and $\mathrm{P}=0.002 ; \mathrm{r}=0.431$ and $\mathrm{P}=0.027 ; \mathrm{r}=0.508$ and $\mathrm{P}<0.001)$ and UACR. Negative correlations between UA, 8-OHdG and eGFR ( $r=-0.301$ and $\mathrm{P}=0.036 ; \mathrm{r}=-0.384$ and $\mathrm{P}=0.002$ ) were registered (Table VI).

\section{Discussion}

In the human body, the progressive increase in the level of uremic toxins exerts a negative impact on all organs, tissues and systems, causing acute and chronic renal dysfunctions, cardiovascular, respiratory and hepatic diseases, atherosclerosis, fibrosis or metabolic alterations (22-25). The presence of UA derivatives is associated with the induction of specific dysfunctions and the normalization of UA levels results in the resolution of the clinical manifestations $(26,27,44-46)$. In terms of chemical structure, uremic toxins are purine, pyrimidine, methylamine, phenyl or indole derivatives, guanidine, polyols, ribonucleosides, peptides, cytokines, advanced glycation end
Table III. Urinary determinations in psoriasis patients and controls.

\begin{tabular}{lccr}
\hline Items & $\begin{array}{c}\text { Psoriasis } \\
\text { vulgaris }\end{array}$ & Control & P-value \\
\hline eGFR $(\mathrm{ml} / \mathrm{min} / 1.73 \mathrm{mp})$ & $95.6 \pm 7.4$ & $102.1 \pm 5.6$ & 0.127 \\
ACR $(\mathrm{mg} / \mathrm{g})$ & $19.3 \pm 11.8$ & $7.8 \pm 5.2$ & 0.050 \\
UACR $(\mathrm{mg} / \mathrm{mg})$ & $0.39 \pm 0.17$ & $0.27 \pm 0.11$ & 0.048
\end{tabular}

eGFR, estimated glomerular filtration rate; ACR, albumin/creatinine ratio; UACR, uric acid/creatinine ratio.

products, advanced lipoxidation end products and reactive carbonyl compounds $(26,27,46)$.

The role played by purine degradation in the pathogenesis of psoriasis is an exciting research topic. The results of the present study on the status of related-purine derivatives in patients with psoriasis indicate changes of the serum level of UA and 8-OHdG and alteration of the enzymatic activities of adenosine deaminase and xanthine oxidase depending on the clinical severity of psoriasis and the stage of renal chronic disease. These results draw attention to the cumulative toxic effect of purine derivatives on the kidney.

In the present study, we obtained slightly increased levels of UA, without statistical significance, in patients with psoriasis versus controls. A significant variation in serum UA levels correlated with the severity of psoriasis. In patients with severe psoriasis, with a PASI score higher than 12 , a significantly increased level of UA was obtained compared for both controls and the group of patients with mild or moderate psoriasis. This was also supported by the positive relationship established between serum UA levels and PASI score and between serum UA levels and the results of the tests assessing the renal function in patients with psoriasis.

Stimulation of epidermal proliferation and increased DNA damage may be associated with hyperuricemia, and the normal UA levels could be explained by the selection criteria of patients [normal body mass index (BMI), lack of inflammation, balanced nutritional status]. In addition, the results of this study show that the risk of kidney disease is more evident in patients with severe psoriasis. Our findings are consistent with several reports that have emphasized harmful effects of UA on kidney, the target organ of hyperuricemia (26-28). Data related to the correlation between serum UA levels and the severity of psoriasis are inconsistent. In some studies, elevated serum values were obtained in patients with psoriasis versus controls (38), whereas other studies reported normal UA levels in psoriasis $(35,37)$. Positive correlations between UA levels and the following parameters have been reported: PASI score, cutaneous extension of psoriatic lesions, and BMI (35).

Elevated levels of serum UA promote endothelial dysfunction and renal lesions by decreasing the availability of nitrogen monoxide and inducing oxidative stress. UA-induced endothelial damage could be caused by the reduction in intracellular ATP due to the inactivation of aconitase-2 and enoyl CoA-hydratase-1, decreased mitochondrial DNA/nuclear DNA ratio, increased mitochondrial calcium, resulting in the 
Table IV. Serum related-purine derivatives levels in psoriasis patients and controls.

\begin{tabular}{lcccc}
\hline & & \multicolumn{3}{c}{ Psoriasis vulgaris PASI score } \\
\cline { 3 - 5 } Items & Control & $<7$ & $7-12$ & $>12$ \\
\hline ADA (UI/mg protein) & $0.14 \pm 0.08$ & $0.20 \pm 0.04$ & $0.24 \pm 0.06$ & $0.38 \pm 0.11$ \\
XO (UI/mg protein) & $0.22 \pm 0.11$ & $0.29 \pm 0.07$ & $0.39 \pm 0.12$ & $0.53 \pm 0.23$ \\
UA (mg/dl) & $5.1 \pm 0.4$ & $3.7 \pm 0.6$ & $5.1 \pm 1.1$ & $5.7 \pm 1.9$ \\
8-OHdG (ng/ml) & $3.1 \pm 0.5$ & $5.2 \pm 2.1$ & $7.9 \pm 2.2$ & $12.4 \pm 7.3$ \\
\hline
\end{tabular}

ADA, adenosine deaminase; XO, xanthine oxidase; UA, uric acid; 8-OHdG, 8-hydroxy-deoxy-guanosine; PASI, psoriasis area and severity index.

Table V. Statistical correlations between serum related-purine derivatives and PASI score.

\begin{tabular}{|c|c|c|c|c|c|c|}
\hline \multirow[b]{2}{*}{ Items } & \multicolumn{2}{|c|}{$<7$} & \multicolumn{2}{|c|}{$7-12$} & \multicolumn{2}{|c|}{$>12$} \\
\hline & $\mathrm{r}$ & $\mathrm{p}$ & $\mathrm{r}$ & $\mathrm{p}$ & $\mathrm{r}$ & $\mathrm{p}$ \\
\hline ADA & 0.094 & 0.353 & 0.137 & 0.062 & 0.498 & 0.004 \\
\hline $\mathrm{XO}$ & 0.103 & 0.281 & 0.095 & 0.413 & 0.601 & $<0.001$ \\
\hline UA & 0.087 & 0.988 & 0.105 & 0.243 & 0.421 & 0.017 \\
\hline 8-OHdG & 0.122 & 0.078 & 0.406 & 0.008 & 0.782 & $<0.001$ \\
\hline
\end{tabular}

ADA, adenosine deaminase; XO, xanthine oxidase; UA, uric acid; 8-OHdG, 8-hydroxy-deoxy-guanosine; PASI, psoriasis area and severity index.

Table VI. Statistical correlations between serum related-purine derivatives and markers of renal impairment in patients with psoriasis.

\begin{tabular}{|c|c|c|c|c|c|c|}
\hline \multirow[b]{2}{*}{ Items } & \multicolumn{2}{|c|}{ ACR } & \multicolumn{2}{|c|}{ UACR } & \multicolumn{2}{|c|}{ eGFR } \\
\hline & $\mathrm{r}$ & $\mathrm{p}$ & $\mathrm{r}$ & $\mathrm{p}$ & $\mathrm{r}$ & $\mathrm{p}$ \\
\hline ADA & 0.111 & 0.564 & 0.297 & 0.032 & -0.088 & 0.512 \\
\hline XO & 0.076 & 0.102 & 0.301 & 0.002 & -0.302 & 0.121 \\
\hline UA & 0.341 & 0.098 & 0.431 & 0.027 & -0.301 & 0.036 \\
\hline 8-OHdG & 0.452 & 0.028 & 0.508 & $<0.001$ & -0.384 & 0.002 \\
\hline
\end{tabular}

ADA, adenosine deaminase; XO, xanthine oxidase; UA, uric acid; 8-OHdG, 8-hydroxy-deoxy-guanosine; ACR, albumin/creatinine ratio; $\mathrm{UACR}$, uric acid/creatinine ratio; eGFR, estimated glomerular filtration rate.

alteration of membrane potential and generation of reactive oxygen species (47). Consequently, endothelial dysfunction can be associated with systemic manifestations (arteriosclerosis, insulin resistance) and renal damage (hypoxia, inflammation, glomerulosclerosis, tubulointerstitial fibrosis) $(47,48)$.

In this study, we revealed that elevated UA levels observed in patients with severe psoriasis were associated with increased xanthine oxidase activity. The serum levels of xanthine oxidase were negatively correlated with eGFR and UACR in urine. The relationship between xanthine oxidase and renal impairment can be explained by the activation of renin-angiotensin system, preglomerular arteriolopathy, induction of oxidative stress and inflammation, and endothelial dysfunctions (49). The role of xanthine oxidase in the terminal differentiation of keratinocytes may be explained by localization of the enzyme in the granular layer of the epidermis (50). The stimulation of the inflammatory process in human keratinocytes by irradiation with UV rays was correlated with the overexpression of xanthine oxidase and increased production of superoxide (51).

Adenosine is another endogenous purine nucleoside, possibly involved in the pathogenesis of psoriasis. It is thought that adenosine may exert anti-inflammatory and immunomodulatory effects through specific receptors expressed on endothelial cells, leukocytes, mast cells, macrophages, dendritic cells and consequently may limit the extension of psoriatic lesions. Antiinflammatory effects of adenosine may be achieved by increasing intracellular cAMP levels, modulation of apoptosis, reduction in cytokine synthesis, leucocyte recruitment and immune function 
regulation (52). The catabolism and bioavailability of adenosine may be modulated by adenosine deaminase (53). In our study, higher serum adenosine deaminase levels were obtained in patients with psoriasis compared to the controls. In addition, the activity of adenosine deaminase was associated with the severity of the disease. In patients with mild or moderate psoriasis, an enhanced adenosine deaminase activity was observed, but no correlation with PASI score was revealed. In patients with severe psoriasis significantly elevated levels of adenosine deaminase were determined compared to those with mild and moderate psoriasis and control group. There was also a strong positive correlation between adenosine deaminase activity and PASI score in patients with severe psoriasis. These findings support the hypothesis that adenosine deaminase could be validated by further studies as a useful indicator in monitoring patients with psoriasis, assessing the response to therapy and predicting the prognosis of the disease $(52,54,55)$. In previous studies on patients with psoriasis, adenosine deaminase activity was found to decline after treatment with PUVA, cyclosporine, etanercept, and psoralen, reconfirming the ability of this enzyme to be associated with T-cell activation $(55,56)$. The increase in adenosine deaminase activity could become a predictive factor for identifying patients with psoriasis at risk of developing relapses prior to the occurrence of clinical manifestations.

An accelerated purine catabolism stimulates the production of free oxygen radicals. The accumulation of reactive oxygen species is associated with changes of DNA structure (oxidation, methylation, single and double strand breaks, cross-links to protein, deletions or translocations) $(57,58)$. In our study, a significant increase in serum levels of $8-\mathrm{OHdG}$ was found in patients with psoriasis versus the controls. The strong correlation between serum concentration of $8-\mathrm{OHdG}$ and PASI score in patients with severe psoriasis and the correlation between 8-OHdG levels and markers of renal impairment suggest that $8-\mathrm{OHdG}$ could favour the onset and/or development of renal disease in patients with psoriasis. In medical literature, there are limited data on the role of $8-\mathrm{OHdG}$ in progressive renal fibrosis $(59,60)$, hypertension associated with proteinuria (61), chronic renal failure (62), diabetes associated with proteinuria $(63,64)$, bladder cancer $(65)$, renal cancer $(66)$ and urothelial carcinoma (67).

Psoriatic arthritis is an important condition associated with psoriasis (68). Regarding urate-lowering drugs, the study by Namazi suggested the beneficial role of allopurinol in the treatment of psoriasis given its ability to neutralize free radicals and inhibit both the secretion of tumour necrosis factor alpha and expression of intercellular adhesion molecule-1 (69). The study by Tsuruta et al concluded that hyperuricemia may be considered an independent risk factor for psoriatic arthritis (70). In addition, findings showed that patients with psoriasis and psoriatic arthritis had an important risk of gout (71).

Taken together, our data and those of the aforementioned studies suggest that severe psoriasis is a risk factor for the development of renal disease. In patients with psoriasis, renal and urinary tract abnormalities have been reported, such as IgA nephropathy, secondary renal amyloidosis, proliferative membranous glomerulonephritis, proliferative mesangial glomerulonephritis, focal proliferative glomerulonephritis, nephrolithiasis and recurrent urinary tract infections $(32,72)$. The relationship between psoriasis and renal disease can be explained by three main mechanisms: Immune-mediated renal damage, drug-related renal damage, and chronic-renal damage (33).

In summary, psoriasis vulgaris can be regarded as a cascade of events that starts from inflammation, oxidative stress and a series of comorbidities. Our study indicates that renal impairment is a frequent condition in patients with psoriasis vulgaris. The related-purine derivatives may be specific serological markers for identifying those patients with psoriasis vulgaris at a high risk of developing renal dysfunctions.

\section{Acknowledgements}

Not applicable.

\section{Funding}

No funding was received.

\section{Availability of data and materials}

All data generated or analyzed during this study are included in this published article.

\section{Authors' contributions}

IN, MT, CM and SRG conceived the study, identified and reviewed the literature. CIM, MIM and MIS collected the data. $\mathrm{CDE}$ and $\mathrm{CE}$ analyzed and interpreted the data. All authors equally contributed to writing the manuscript, and CDE and $\mathrm{CE}$ edited and revised the manuscript. All authors read and approved the final version of the manuscript.

\section{Ethics approval and consent to participate}

The study was approved by the Ethics Committee of 'Victor Babes' Clinical Hospital for Infectious Diseases (Bucharest, Romania). All the participants gave their consent to the use of their biological samples in research studies.

\section{Patient consent for publication}

Not applicable.

\section{Competing interests}

The authors declare that they have no competing interests.

\section{References}

1. Davidovici BB, Sattar N, Prinz J, Puig L, Emery P, Barker JN van de Kerkhof P, Ståhle M, Nestle FO, Girolomoni G and Krueger JG: Psoriasis and systemic inflammatory diseases: Potential mechanistic links between skin disease and co-morbid conditions. J Invest Dermatol 130: 1785-1796, 2010.

2. Kölliker Frers RA, Bisoendial RJ, Montoya SF, Kerzkerg E, Castilla R, Tak PP, Milei J and Capani F: Psoriasis and cardiovascular risk: Immune-mediated crosstalk between metabolic, vascular and autoimmune inflammation. IJC Metab Endocr 6: 43-54, 2015.

3. Sârbu MI, Georgescu SR, Tampa M, Sârbu AE and Simionescu O: Biological therapies in psoriasis - revisited. Rom J Intern Med 56: 75-84, 2018. 
4. Murari K, Ray AS and Lodha RS: Adenosine deaminase: A potential biomarker for evaluating the severity of psoriasis. Int J Pharma Bio Sci 6: 629-634, 2015.

5. Shree UGB, Vishal B, Shindhu M, Shenoy MM and Shenoy C: Advanced oxidation protein product in psoriasis and its correlation with disease severity. Int J Sci Stud 2: 156-159, 2015.

6. Basavaraj KH, Vasu Devaraju P and Rao KS: Studies on serum 8-hydroxy guanosine (8-OHdG) as reliable biomarker for psoriasis. J Eur Acad Dermatol Venereol 27: 655-657, 2013.

7. Nwabudike LC and Tatu AL: Reply to Happle R. And al. Koebners sheep in Wolf's clothing: Does the isotopic response exist as a distinct phenomenon? J Eur Acad Dermatol Venereol 32 336-337, 2018

8. Tampa M, Sarbu MI, Mitran MI, Mitran CI, Matei C and Georgescu SR: The pathophysiological mechanisms and the quest for biomarkers in psoriasis, a stress-related skin disease. Dis Markers 2018: 5823684, 2018.

9. Căruntu C, Boda D, Căruntu A, Rotaru M, Baderca F and Zurac S: In vivo imaging techniques for psoriatic lesions. Rom J Morphol Embryol 55: 1191-1196, 2014.

10. Batani A, Brănisteanu DE, Ilie MA, Boda D, Ianosi S, Ianosi G and Caruntu C: Assessment of dermal papillary and microvascular parameters in psoriasis vulgaris using in vivo reflectance confocal microscopy. Exp Ther Med 15: 1241-1246, 2018

11. Negrei C, Arsene AL, Toderescu CD, Boda D and Ilie M: Acitretin treatment in psoriasis may influence the cell membrane fluidity. Farmacia 60: 767-772, 2012.

12. Nicolae I,Ene CD, Schipor S, Tampa M, Matei C and Georgescu SR Dopamine-chemical mediator in atopic dermatitis. Rev Chim 64: 1201-1206, 2013

13. Negrei C, Ginghină O, Căruntu C, Burcea Dragomiroiu GT, Jinescu GE and Boda DA: Investigation relevance of methotrexate polyglutamates in biological systems by high performance liquid chromatography. Rev Chim 66: 766-768, 2015.

14. Caruntu C, Boda D, Dumitrascu G, Constantin C and Neagu M: Proteomics focusing on immune markers in psoriatic arthritis. Biomarkers Med 9: 513-528, 2015.

15. Gisondi P, Galvan A, Idolazzi L and Girolomoni G: Management of moderate to severe psoriasis in patients with metabolic comorbidities. Front Med (Lausanne) 2: 1, 2015

16. Sarbu MI, Tampa M, Matei C, Mitran CI, Mitran MI, Pituru S, Pop CS, Saramet G and Georgescu SR: Infliximab biosimilar versus methotrexate for the treatment of moderate to severe psoriasis. Farmacia 65: 962-967, 2017.

17. Wan J, Wang S, Haynes K, Denburg MR, Shin DB and Gelfand JM: Risk of moderate to advanced kidney disease in patients with psoriasis: Population based cohort study. BMJ: Oct 15, 2013 (Epub ahead of print). doi: https://doi.org/10.1136/ bmj.f5961.

18. Chi CC, Wang J, Chen YF, Wang SH, Chen FL and Tung TH Risk of incident chronic kidney disease and end-stage renal disease in patients with psoriasis: A nationwide population-based cohort study. J Dermatol Sci 78: 232-238, 2015.

19. Negrei C,Caruntu C, Ginghina O, Dragomiroiu GT, Toderescu CD and Boda D: Qualitative and quantitative determination of methotrexate polyglutamates in erythrocytes by high performance liquid chromatography. Rev Chim 66: 607-610, 2015.

20. Sârbu MI, Tampa M, Mitran MI, Mitran CI, Limbău AM and Georgescu SR: Adverse reactions of biological therapies in patients with psoriasis. J Mind Med Sci 4: 4-12, 2017.

21. Lisowska-Myjak B: Serum and urinary biomarkers of acute kidney injury. Blood Purif 29: 357-365, 2010.

22. Hsu HJ, Yen CH, Wu IW, Hsu KH, Chen CK, Sun CY, Chou CC, Chen CY, Tsai CJ, Wu MS, et al: The association of uremic toxins and inflammation in hemodialysis patients. PLoS One 9 e102691, 2014

23. Xu G, Tu W and Qin S: The relationship between deiodinase activity and inflammatory responses under the stimulation of uremic toxins. J Transl Med 12: 239, 2014.

24. Duranton F, Cohen G, De Smet R, Rodriguez M, Jankowski J, Vanholder R and Argiles A; European Uremic Toxin Work Group: Normal and pathologic concentrations of uremic toxins. J Am Soc Nephrol 23: 1258-1270, 2012

25. Boueiz A, Damarla M and Hassoun PM: Xanthine oxidoreductase in respiratory and cardiovascular disorders. Am J Physiol Lung Cell Mol Physiol 294: 830-840, 2008.

26. Lisowska-Myjak B and Skarżyńska E: Role of uremic compounds in organ injury. J Nephrol Ther 5: 1000205, 2015.

27. Lisowska-Myjak B: Uremic toxins and their effects on multiple organ systems. Nephron Clin Pract 128: 303-311, 2014.
28. Xia JF, Liang QL, Hu P, Wang YM, Li P and Luo GA: Correlations of six related purine metabolites and diabetic nephropathy in Chinese type 2 diabetic patients. Clin Biochem 42: 215-220, 2009.

29. Xia J, Wang Z and Zhang F: Association between related purine metabolites and diabetic retinopathy in type 2 diabetic patients. Int J Endocrinol: Feb 13, 2014 (Epub ahead of print). doi: $10.1155 / 2014 / 651050$.

30. Avci E, Cakir E, Cevher SC, Yaman H, Agilli M and Bilgi C: Determination of oxidative stress and cellular inflammation in patients with diabetic nephropathy and non-diabetic nephropathy being administered hemodialysis treatment due to chronic renal failure. Ren Fail 36: 767-773, 2014

31. Ishikawa T, Aw W and Kaneko K: Metabolic interactions of purine derivatives with human $\mathrm{ABC}$ transporter $\mathrm{ABCG}$ : Genetic testing to assess gout risk. Pharmaceuticals (Basel) 6: 1347-1360, 2013.

32. Dervisoglu E, Akturk AS, Yildiz K, Kiran R and Yilmaz A: The spectrum of renal abnormalities in patients with psoriasis. Int Urol Nephrol 44: 509-514, 2012.

33. Visconti L, Leonardi G, Buemi M, Santoro D, Cernaro V, Ricciardi CA, Lacquaniti A and Coppolino G: Kidney disease and psoriasis: Novel evidences beyond old concepts. Clin Rheumatol 35: 297-302, 2016.

34. Boda D, Negrei C, Nicolescu F and Bălălău CR: Assessment of some oxidative stress parameters in methotrexate treated psoriasis patients. Farmacia 62: 704-710, 2014

35. Kwon HH, Kwon IH, Choi JW and Youn JI: Cross-sectional study on the correlation of serum UA with disease severity in Korean patients with psoriasis. Clin Exp Dermatol 36: 473-478, 2011.

36. Christophers E and Mrowietz U: Psoriasis. In: Fitzpatrick's dermatology in general medicine. Freedberg IM, Eisen AS, Wolff K, Austen KF, Goldsmith LA and Katz SI (eds). Vol 1. 6th edition. McGraw-Hill, New York, NY, pp407-427, 2003.

37. Ataseven A, Kesli R, Kurtipek GS and Ozturk P: Assessment of lipocalin 2, clusterin, soluble tumor necrosis factor receptor-1, interleukin-6, homocysteine, and UA levels in patients with psoriasis. Dis Markers 2014: 541709, 2014. doi: $10.1155 / 2014 / 541709$.

38. Gisondi P, Targher G, Cagalli A and Girolomoni G: Hyperuricemia in patients with chronic plaque psoriasis. J Am Acad Dermatol 70: 127-130, 2014.

39. Ciragil P, Kurutas EB and Miraloglu M: New markers: Urine xanthine oxidase and myeloperoxidase in the early detection of urinary tract infection. Dis Markers 2014: 269362, 2014. doi: org/10.1155/2014/269362

40. Vorbach C, Harrison R and Capecchi MR: Xanthine oxidoreductase is central to the evolution and function of the innate immune system. Trends Immunol 24: 512-517, 2003.

41. Tampa M, Nicolae I, Ene CD, Sarbu I, Matei C and Georgescu SR: Vitamin $\mathrm{C}$ and thiobarbitUA reactive substances (Tbars) in psoriasis vulgaris related to psoriasis area severity index (Pasi). Rev Chim 68: 43-47, 2017.

42. Matei C, Tampa M, Caruntu C, Ion RM, Georgescu SR, Dumitrascu GR, Constantin C and Neagu M: Protein microarray for complex apoptosis monitoring of dysplastic oral keratinocytes in experimental photodynamic therapy. Biol Res 47: 33, 2014.

43. Dinu LU, Ene CD, Nicolae IL, Tampa M, Matei CL and Georgescu SR: The serum levels of 8-hidroxy-deoxyguanosine under the chemicals influence. Rev Chim 65: 1319-1326, 2014.

44. Barreto FC, Stinghen AE, de Oliveira RB, Franco AT, Moreno AN, Barreto DV, Pecoits-Filho R, Drüieke TB and Massy ZA: The quest for a better understanding of chronic kidney disease complications: An update on uremic toxins. J Bras Nefrol 36: 221-235, 2014.

45. Glorieux G and Tattersall J: Uraemic toxins and new methods to control their accumulation: Game changers for the concept of dialysis adequacy. Clin Kidney J 8: 353-362, 2015.

46. Semchyshyn HM: Reactive carbonyl species in vivo: Generation and dual biological effects. ScientificWorldJournal 2014: 417842, 2014. doi: 10.1155/2014/417842.

47. Sánchez-Lozada LG, Lanaspa MA, Cristóbal-García M, García-Arroyo F, Soto V, Cruz-Robles D, Nakagawa T, Yu MA, Kang DH and Johnson RJ: UA-induced endothelial dysfunction is associated with mitochondrial alterations and decreased intracellular ATP concentrations. Nephron, Exp Nephrol 121: 71-78, 2012.

48. Davidovici BB, Sattar N, Prinz J, Puig L, Emery P, Barker JN, van de Kerkhof P, Ståhle M, Nestle FO, Girolomoni G, et al: Psoriasis and systemic inflammatory diseases: Potential mechanistic links between skin disease and co-morbid conditions. J Invest Dermatol 130: 1785-1796, 2010 . 
49. Kim IY, Lee DW, Lee SB and Kwak IS: The role of UA in kidney fibrosis: Experimental evidences for the causal relationship BioMed Res Int 2014: 638732, 2014. doi: 10.1155/2014/638732.

50. Reiners JJ Jr and Rupp T: Conversion of xanthine dehydrogenase to xanthine oxidase occurs during keratinocyte differentiation: Modulation by 12-O-tetradecanoylphorbol-13-acetate. J Invest Dermatol 93: 132-135, 1989.

51. Deliconstantinos G, Villiotou V and Stavrides JC: Alterations of nitric oxide synthase and xanthine oxidase activities of human keratinocytes by ultraviolet $B$ radiation. Potential role for peroxynitrite in skin inflammation. Biochem Pharmacol 51: 1727-1738, 1996.

52. Festugato M: Adenosine: An endogenous mediator in the pathogenesis of psoriasis. An Bras Dermatol 90: 862-867, 2015.

53. Maiuolo J, Oppedisano F, Gratteri S, Muscoli C and Mollace V: Regulation of UA metabolism and excretion. Int J Cardiol 213 $8-14,2016$.

54. Coimbra S and Santos-Silva A: Biomarkers of psoriasis severity and therapy monitoring. World J Dermatol 3: 15-27, 2014.

55. Y1ldırım FE, Karaduman A, Pinar A and Aksoy Y: CD26/ dipeptidyl-peptidase IV and adenosine deaminase serum levels in psoriatic patients treated with cyclosporine, etanercept, and psoralen plus ultraviolet A phototherapy. Int J Dermatol 50: 948-955, 2011

56. Bukulmez G, Akan T and Ciliv G: Serum adenosine deaminase levels in patients with psoriasis: A prospective case-control study. Eur J Dermatol 10: 274-276, 2000.

57. Nicolae I: ENE CD, Georgescu SR, Tampa M, Matei C, Ceausu E: Effects of UV radiation and oxidative DNA adduct 8-hydroxy-2'-deoxiguanosine on the skin diseases. Rev Chim 65: 1036-1041, 2014.

58. Birben E, Sahiner UM, Sackesen C, Erzurum S and Kalayci O Oxidative stress and antioxidant defense. World Allergy Organ J 5: 9-19, 2012

59. Remuzzi G and Bertani T: Pathophysiology of progressive nephropathies. N Engl J Med 339: 1448-1456, 1998.

60. Tsai JP, Liou JH, Yeh KT, Tai HC, Cheng YW and Chang HR: Intensity of cytosol expression of $8-\mathrm{OHdG}$ in normal renal tubules is associated with the severity of renal fibrosis. Swiss Med Wkly 141: w13268, 2011.
61. Dincer Y, Sekercioglu N, Pekpak M, Gunes KN and Akcay T: Assessment of DNA oxidation and antioxidant activity in hypertensive patients with chronic kidney disease. Ren Fail 30 1006-1011, 2008

62. Domenici FA, Vannucchi MT, Jordão AA Jr, Meirelles MS and Vannucchi H: DNA oxidative damage in patients with dialysis treatment. Ren Fail 27: 689-694, 2005.

63. Shah SV, Baliga R, Rajapurkar M and Fonseca VA: Oxidants in chronic kidney disease. J Am Soc Nephrol 18: 16-28, 2007.

64. Jeong KH, Lee TW, Ihm CG, Lee SH, Moon JY and Lim SJ: Effects of sildenafil on oxidative and inflammatory injuries of the kidney in streptozotocin-induced diabetic rats. Am J Nephrol 29: 274-282, 2009.

65. Akçay T, Saygili I, Andican G and Yalçin V: Increased formation of 8-hydroxy-2'-deoxyguanosine in peripheral blood leukocytes in bladder cancer. Urol Int 71: 271-274, 2003.

66. Miyake H, Hara I, Kamidono S and Eto H: Prognostic significance of oxidative DNA damage evaluated by 8-hydroxy2 -deoxyguanosine in patients undergoing radical nephrectomy for renal cell carcinoma. Urology 64: 1057-1061, 2004.

67. Chang $\mathrm{CH}$, Yang $\mathrm{CM}$ and Yang AH: Renal diagnosis of chronic hemodialysis patients with urinary tract transitional cell carcinoma in Taiwan. Cancer 109: 1487-1492, 2007.

68. Tatu AL and Nwabudike LC: Metoprolol-associated onset of psoriatic arthropathy. Am J Ther 24: e370-e371, 2017.

69. Namazi MR: Cannabinoids, loratadine and allopurinol as novel additions to the antipsoriatic ammunition. J Eur Acad Dermatol Venereol 19: 319-322, 2005

70. Tsuruta N, Imafuku S and Narisawa Y: Hyperuricemia is an independent risk factor for psoriatic arthritis in psoriatic patients. J Dermatol 44: 1349-1352, 2017.

71. Merola JF, Wu S, Han J, Choi HK and Qureshi AA: Psoriasis, psoriatic arthritis and risk of gout in US men and women. Ann Rheum Dis 74: 1495-1500, 2015.

72. Singh NP, Prakash A, Kubba S, Ganguli A, Singh AK, Sikdar S, Agarwal SK, Dinda AK and Grover C: Psoriatic nephropathy - does an entity exist? Ren Fail 27: 123-127, 2005. 